\title{
Study on the Calculation of Thermodynamic Properties of R134a Using Cubic Equations of State
}

\author{
Hong Xiao ${ }^{1, a^{*}}$ and Hui Liu ${ }^{2, b}$ \\ ${ }^{1}$ School of Computer Science, Xi'an Shiyou University,Shannxi ,Xi'an 710065,China \\ ${ }^{2}$ School of Mechanical Engineering, Xi'an Shiyou University,Shannxi ,Xi'an 710065,China \\ a xiaohong@xsyu.edu.cn ,b liuhui@xsyu.edu.cn
}

Keywords: R134a; Thermodynamic properties; Cubic equations of state

\begin{abstract}
The volume of saturated vapor and saturated liquid of R134a were calculated by using four cubic equations of state: SRK,PR ,T-L and S-Y. Calculation shows that in the range of $-50 \sim$ $90{ }^{\circ} \mathrm{C}$, the $\mathrm{T}-\mathrm{L}$ equation of state has the highest calculating accuracy, the average deviations of calculation of saturated vapor volume and saturated liquid volume being $1.63 \%$ and $4.12 \%$ respectively. Those of PR equation are $1.90 \%$ and $4.76 \%$, while the average deviations of calculation of SRK equation are $3.35 \%$ and 18 . 64\% respectively, the largest of the four equations of state for either saturated vapor or saturated liquid. S-Y equation has equal accuracy of calculation with PR equation, the average deviations being $2.00 \%$ for saturated vapor and $5.21 \%$ for saturated liquid. T-L equation of state is recommended to calculate thermodynamic properties of R34a for engineering purposes.
\end{abstract}

\section{Introduction}

$\mathrm{R} 34 \mathrm{a}$ is an environment-friendly refrigerant . Since it does not contain chlorine and there is no damage effect to the ozone layer of the atmosphere, R134a is widely used in air-conditioning or refrigeration equipment.

Equations of state have played an essential role in the calculation of thermodynamic properties of refrigerants[1]. Cubic equations of state is widely used to calculate thermal properties of refrigerants duo to its simple form and reasonable accuracy[2]. Although their calculation accuracy is not as high as that of multiple constant equations of state, they are simple in form and convenient in use and therefore welcomed by engineers. It is still meaningful to seek new cubic equations of state with higher accuracy of calculation to refrigerants.

\section{Choice of Cubic Equations of State}

Equations of state, SRK[3] and PR[4], are two classic equations and widely used in petrochemical industry and refrigeration engineering, but these two equations are not strictly suitable polar fluid such as $\mathrm{R} 134 \mathrm{a}, \mathrm{NH}_{3}$, etc[5]. In order to improve the accuracy of calculation for polar working substances, new cubic equations of state have been proposed[6-10]. And in this paper two new cubic equations of state, T-L[6] and S-Y[7], are chosen to calculate the thermodynamic properties of R134a, because they were said to be suitable for polar gas with higher accuracy . By using the four equations of state, SRK, PR, T-L and S-Y, specific volumes of saturated vapor and liquid of R134a are calculated and the calculated values are compared with the values of literature[5]. We hope to choose a cubic equation of state that has higher accuracy of calculation for R134a than RK and PR equations.

SRK Equation of State[3].

SRK equation of state proposed by Soave G. is widely used in both scientific research and industrial sectors.Eccentric factor of fluid is introduced into the equation. SRK equation is as follows:

$$
p=\frac{R T}{V-b}-\frac{a(T)}{V(V+b)}
$$




$$
\begin{aligned}
& a(T)=a\left(T_{c}\right) \cdot \alpha(T) \\
& a\left(T_{c}\right)=0.42748 R^{2} T_{c}^{2} / p_{c} \\
& b=0.08664 R T_{c} / p_{c} \\
& \alpha^{0.5}(T)=1+m\left[1-\left(T / T_{c}\right)^{0.5}\right] \\
& m=0.480+1.574 \omega-0.176 \omega^{2}
\end{aligned}
$$

\section{PR Equation of State [3]}

PR equation of state was proposed by Peng and Robinson .PR equation is as follows:

$$
p=\frac{R T}{V-b}-\frac{a(T)}{V(V+b)+b(v-b)}
$$

$a(T)=a\left(T_{c}\right) \cdot \alpha(T)$

$a\left(T_{c}\right)=0.45724 R^{2} T_{c}^{2} / p_{c}$

$b=0.0778 R T_{c} / p_{c}$

$\alpha^{0.5}(T)=1+m\left[1-\left(T / T_{c}\right)^{0.5}\right]$

$m=0.37464+1.54226 \omega-0.26992 \omega^{2}$

\section{T - L Equation of State[6]}

L-T equation, proposed in 1982 , is an cubic equation of state with improved accuracy of calculation for polar fluid. $\mathrm{L}-\mathrm{T}$ equation is as follows:

$$
\begin{aligned}
& p=\frac{R T}{V-b}-\frac{a(T)}{(V+m b)(V-n b)} \\
& a(T)=a\left(T_{c}\right) \cdot \alpha(T) \\
& m=1+\sqrt{8 \omega}, n=2(\sqrt{2}-1) \sqrt{\omega} \\
& a\left(T_{c}\right)=\Omega_{a} R^{2} T_{c}^{2} / p_{c} \\
& \Omega_{a}=\varsigma_{c}^{2} / \beta_{c}+m n \beta_{c} \varsigma_{c}^{2}\left(1+\beta_{c} \varsigma_{c}\right) \\
& b=\Omega_{b} R T_{c} / p_{c}, \Omega_{b}=\beta_{c} \varsigma_{c} \\
& \beta_{c}=0.25990-0.16824 \omega+0.75622 \omega^{2}-0.80732 \omega^{3}
\end{aligned}
$$




$$
\begin{aligned}
& \varsigma_{c}=1 /\left(2 \sqrt{\omega} \beta_{c}+3\right) \\
& \alpha^{0.5}(T)=1+m\left[1-\left(T / T_{c}\right)^{0.5}\right] \\
& m=\left[\left(0.34 / Z_{c}\right)^{4}-1\right] / 2
\end{aligned}
$$

\section{S -Y Equation of State [7]}

Su Zhijun and Yan Jialu proposed a new cubic equation of state ( S-Y equation ). The critical compression factor is introduced into the equation in order to make the equation more suitable for polar fluid. Su-Yan equation is as follows:

$$
\begin{aligned}
& p=\frac{R T}{v-b}-\frac{a(T)}{v^{2}+u b v+(1-u) b} \\
& u=-8.51054 \ln Z_{c}-9.34689 \\
& a(T)=a\left(T_{c}\right) \cdot \alpha(T) \\
& \alpha^{0.5}(T)=1+m\left[1-\left(T / T_{c}\right)^{0.5}\right] \\
& m=0.44865+1.40158 \omega-0.64387 \omega^{2} \\
& a\left(T_{c}\right)=\Omega_{a} R^{2} T_{c}^{2} / p_{c} \\
& b=\Omega_{b} R T_{c} / p_{c} \\
& \Omega_{a}=0.39658+3.3139 \times 10^{-2} u-1.4766 \times 10^{-3} u^{2} \\
& \Omega_{b}=0.095653+-9.9939 \times 10^{-3} u+5.7049 \times 10^{-4} u^{2}
\end{aligned}
$$

The four equations of state will be applied to calculate.

\section{Results of Calculation}

The saturated liquid volumes and saturated vapour volumes of R134a were calculated in the temperature range of $-50 \sim 90{ }^{\circ} \mathrm{C}$, the interval being $10{ }^{\circ} \mathrm{C}$, by using the four equations of state above-mentioned. The calculated values are compared with the values in the literature[5]. The deviation of calculated values and values of the literature are shown in Table 1. The relative deviation and average deviation of calculation are determined according to the following formulas:

Relative deviation

$$
\delta_{i}=\frac{x_{i}-x_{i}^{*}}{x_{i}} \times 100 \%
$$

Where $x_{i}$ is the calculated value with the equation of state, $x_{i}^{*}$ is the value from literature. 
$\bar{\delta}=\sum_{i}\left|\delta_{i}\right| / N$

Where $N$ is the number of points of calculation .

Table 1 Deviations of calculation for specific volumes of R34a

$(\%)$

\begin{tabular}{|c|c|c|c|c|}
\hline \multirow{2}{*}{ EOS } & \multicolumn{2}{|c|}{ Saturated Liquid } & \multicolumn{2}{c|}{ Saturated Vapour } \\
\cline { 2 - 5 } & $\begin{array}{c}\text { average } \\
\text { Deviation }\end{array}$ & $\begin{array}{c}\text { maximum } \\
\text { deviation }\end{array}$ & $\begin{array}{c}\text { average } \\
\text { deviation }\end{array}$ & $\begin{array}{c}\text { maximum } \\
\text { deviation }\end{array}$ \\
\hline SRK & 18.6 & 34.8 & 3.35 & 5.58 \\
\hline PR & 4.76 & 19.6 & 1.91 & 3.08 \\
\hline SY & 5.21 & 21.6 & 2.00 & 3.16 \\
\hline LT & 4.12 & 22.7 & 1.63 & 2.87 \\
\hline
\end{tabular}

As can been seen from the table 1 , for calculation of saturated liquid volume T-L equation gives minimum average deviation of $4.12 \%$, the PR equation $4.76 \%$, S-Y equation $5.21 \%$, and SRK equation $18.6 \%$. Although the maximum deviations of the four equations are quite high, they all appear in $90{ }^{\circ} \mathrm{C}$, near the critical temperature of R34a. The deviation of calculation of T-L equation is the least in the temperature range away from the critical point among the four equations mentioned. PR equation ranges the second in accuracy, and SRK equation is the worst of the equations involved.

The table 1 indicates that for the volumes of saturated vapour, T-L equation gives the average deviation of $1.63 \%$ and the maximum deviation is $2.87 \%$, both being the least of the four equations. Both the average and maximum deviations of SRK equation are a little higher than that of other equations. The average deviation and maximum deviation of PR equation are $1.91 \%$ and $3.08 \%$, respectively. S-Y equation has roughly equal average deviation and maximum deviation with PR equation.

\section{Conclusion}

Four cubic equations of state, SRK, PR, S-Y and T-L, are discussed for the calculation of thermodynamic properties of environment-friendly refrigerant R34a. T-L equation, with the least deviations of calculation for both saturated liquid and saturated vapour, is recommended to be applied in the calculation of air conditioning and refrigeration for engineering purposes.

Symbols instructions

$\mathrm{P}$ - pressure, $\mathrm{kPa}$

$\mathrm{R}$ - constant of gas, $\mathrm{kJ} /(\mathrm{kg} \cdot \mathrm{K})$

$\mathrm{T}$ - thermodynamic temperature, $\mathrm{K}$

$\mathrm{v}$ - specific volume, $\mathrm{m} 3 / \mathrm{kg}$

$\omega$ - eccentric factor

$\mathrm{Zc}$ - compressibility factor

subscript

c- critical point

$\mathrm{r}$ - reduced state 


\section{References}

[1] W. S. Dao and J. G. Tong: Engineering Thermodynamics (Higher Education Press, China,2016),p 202.

[2] Y. R. Ma: Calculationn of Thermodynamic Rroperties of Refrigerants and Performances of Refrigeration Cycle with PR Equation of State (PH.D., Northwest Polytechnical university, China,2009). p.15.

[3] Soave G: Equilibrium Constants from a Modified Redlich - Kwong Equation of State. Chem. Engng. Sci. Vol.27(1972)No.6,p1197.

[4] Y, Peng, Robinson D B. A New Two - constant Equation of State . Ind. Engng. Chem. Fundam, Vol.15(1976)No.1,p15.

[5] Z. S. Chen: Advanced Engineering Thermodynamics (Higher Education Press, China,2015), p.95. Beijing: higher education press, 2015

[6] J. S. Tong and Y. P. Liu: Journal of Engineering Thermophysics. Vol. 3 (1982)No.3, p 6.

[7] Z. J. Su and J. L. Yan: Journal of Engineering Thermophysics, Vol. 27(2007) No.3, p18.

[8] H. Lin and Y. Y. Duan : Journal of Engineering Thermophysics, Vol.29(2008)No.1, p11.

[9] H. X. Wang and C. M. Zheng: Journal of Tianjin University ,Vol.38(2008), 6.

[10] Y. B. Liang and J. S.Tong: , Journal of Engineering Thermophysics, Vol.32(2011)No.1,p11. 